\title{
Endoscopic resection of giant esophageal fibrovascular polyp
}

\author{
lyad Khamaysi ${ }^{1}$ (D), Yousef Abu Asbeh² (D) \\ ${ }^{1}$ Department of Gastroenterology and Hepatology, Technion-Israel Institute of Technology, Rappaport School of Medicine, Haifa, Israel \\ 2Department of Chest Surgery, Rambam Health Care Campus, Haifa, Israel
}

Cite this article as: Khamaysi I, Asbeh YA. Endoscopic resection of giant esophageal fibrovascular polyp. Turk J Gastroenterol 2020; 31(3): $276-8$.

\section{Dear Editor,}

Fibrovascular polyps of the esophagus account for $0.5-1 \%$ of benign esophageal lesions and are quite rare, of all benign.

Most of these polyps arise from the upper third of the esophagus. Typically, these lesions are attached to the inferior aspect of the cricopharyngeal muscle. Fibrovascular polyps are characterized by the development of pedunculated, intraluminal processes that can grow to enormous proportions. Histologically, the polyps are composed of loose or dense fibrous tissue, adipose tissue, and vascular structures lined by normal squamous epithelium. Dysphagia and chest discomfort are the most frequent complaints. However, long pedunculated lesions can regurgitate into the pharynx or mouth and might occlude the larynx $(1,2)$. Herein, we present a case with giant esophageal fibrovascular polyp that was initially scheduled for surgical resection, but was later removed endoscopically.

A 57-year-old female patient, with medical history remarkable only for phenylketonuria and right thoracotomy (for enucleation of leiomyoma from the distal esophagus) twenty-six years ago. Few months prior to her presentation, the patient suffered from gradual dysphagia and chest discomfort. The dysphagia was initially for solid food and later for both food and liquid, which resulted in a weight loss of 6 kilograms over the past 4 months. The patient also described a transient regurgitation of soft mass. The patient underwent upper gastrointestinal endoscopy that showed a huge esophageal double-headed polyp arising from a stalk (Figure 1) attached to the upper esophagus, $15-16 \mathrm{~cm}$ from incisors (distal to the upper esophageal sphincter). The polyp was $16 \mathrm{~cm}$ in length with normal epithelial coverage. Multiple biopsies were obtained. Histopathologically, the lesion was diagnosed as benign fibroepithelial polyp of esophagus. The lesion was also demonstrated by computed tomography scan of the chest (Figure 2).
The patient's case was discussed in a multidisciplinary team meeting where it was decided that upper endoscopic resection of the lesion would be performed, along with preparation for possible right thoracotomy and transesophageal resection of the mass, in case endoscopic resection or iatrogenic perforation of the esophagus is not possible.

After tracheal intubation, upper endoscopy was performed under general anesthesia. The massive double-headed polyp occluding the esophageal lumen was identified with the stalk arising at the uppermost esophagus. First, two metal endoscopic clips (Sureclip plus endoclip, Micro-Tech Endoscopy, Nanjing) were inserted over the stalk, and an extra-large snare (Micro-Tech Endoscopy, Nanjing) was used to capture the two heads of the polyp one by one, until the snare was fixed over the stalk. The stalk was resected distal to the endoclips.

The resected polyp could not be removed en-block; hence, it was pushed down to the stomach, divided by the snare into two pieces and extracted out per os (Figure 3). Inspec-

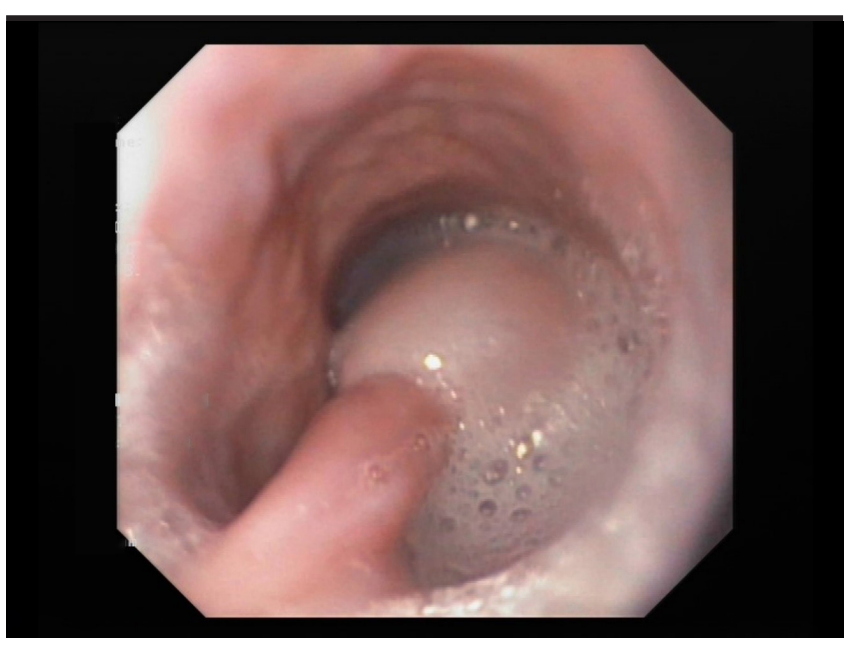

Figure 1. Endoscopic view of the stalk of the polyp. 

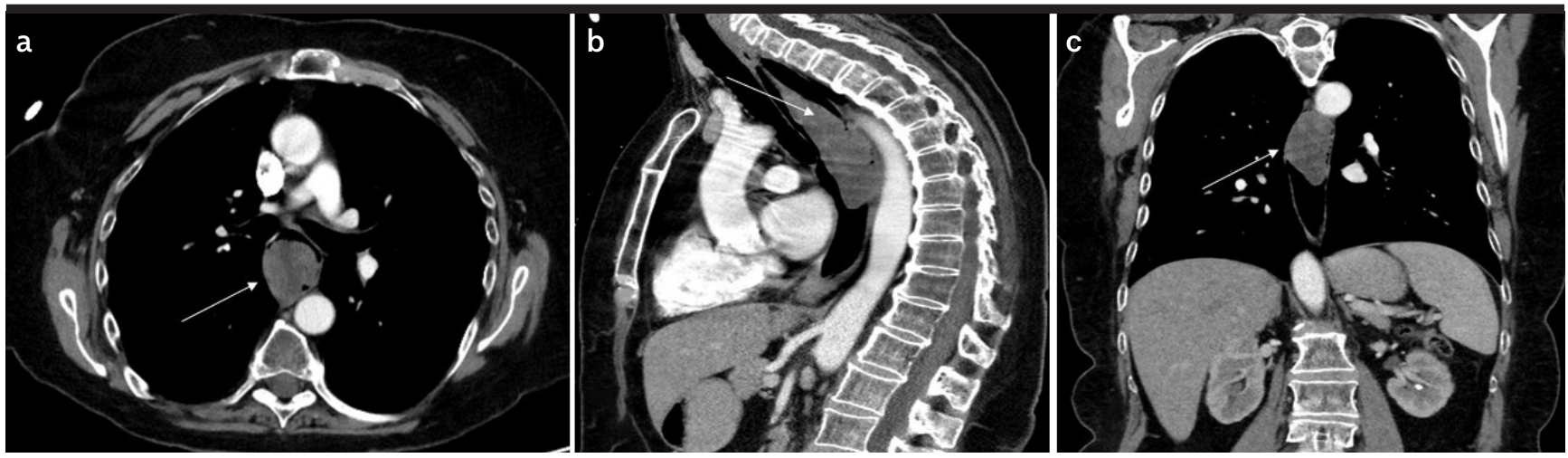

Figure 2. a-c. Computed tomography scan of the chest showing the polyp (arrow). (a) axial view, (b) sagittal view, (c) coronal view.

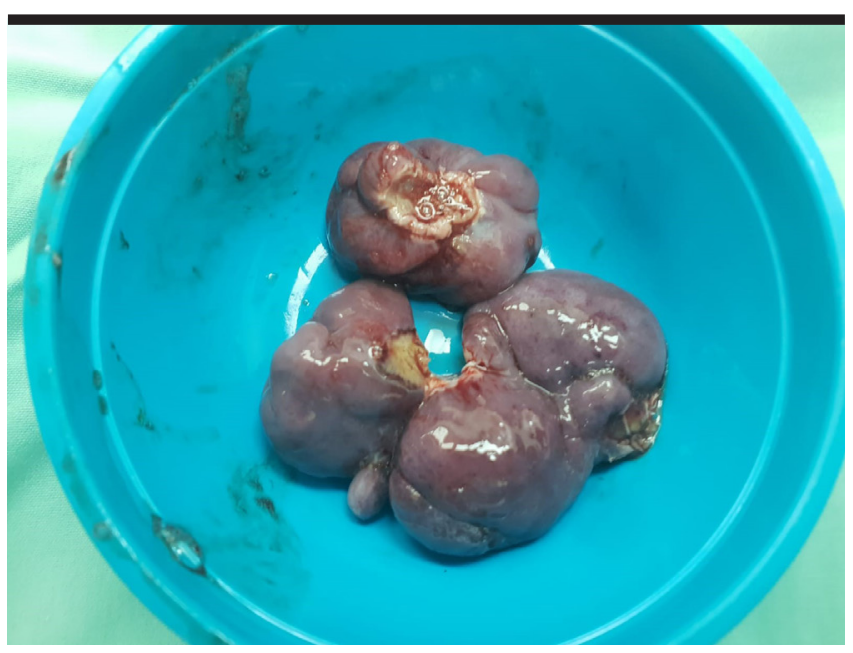

Figure 3. The resected polyp divided into two pieces.

tion of the esophageal wall revealed no signs of bleeding, deep injury, or perforation. Regular food was resumed $24 \mathrm{~h}$ later and the patient was discharged on the second post-operative day. The dysphagia and chest discomfort resolved completely. The final pathologic report confirmed a fibrovascular esophageal polyp.

Fibrovascular polyps of the esophagus are rare, benign, nonneoplastic intraluminal masses. Most published reports on patients with these polyps have been anecdotal. Most common presenting symptoms are dysphagia $(87 \%)$ and respiratory symptoms (25\%) (3). Case reports have described prolapse of large lesions into the larynx, causing asphyxiation (4).

Fibrovascular polyps often have a stalk, which may aid endoscopic resection at experienced centers. The endoscopic resection might be more challenging in case of proximally attached stalks (5). Surgical resection might be indicated over endoscopic resection in case of large feeding vessel throughout the stalk, or in case of endoscopically inaccessible stalk. Some centers perform endoscopic ultrasound prior to endoscopic resection to rule out large feeding vessels.

Avoiding the morbidity and mortality associated with thoracotomy whenever possible has a great impact on the short and long-term well-being of the patients. Our patient had a short hospital course, uneventful post-operative course, and was able to return to work one week after the procedure.

Informed Consent: Written informed cinsent was obtained by the patient participated in this study.

Peer-review: Externally peer-reviewed.

Author Contributions: Concept - I.K.; Design - I.K., Y.A.; Supervision - I.K., Y.A.; Resource - I.K., Y.A.; Materials - I.K., Y.A.; Data Collection and/or Processing - I.K., Y.A.; Analysis and/or Interpretation - I.K., Y.A.; Literature Search - I.K., Y.A.; Writing - I.K., Y.A.; Critical Reviews - I.K.

Conflict of Interest: The authors have no conflicts of interest to declare.

Financial Disclosure: The authors declared that this study has received no financial support.

\section{REFERENCES}

1. Palanivelu C, Rangarajan M, John SJ, Annapoorni S, Senthilkumar $S$. A rare cause of intermittent dysphagia: giant fibrovascular polyp of the proximal esophagus. J Coll Physicians Surg Pak 2007; 17: 51-2. 2. Chourmouzi D, Drevelegas A. Giant fibrovascular polyp of the oesophagus: a case report and review of the literature. J Med Case Rep 2008; 2: 337. [Crossref]

3. Levine MS, Buck JL, Pantongrag-Brown L, Buetow PC, Hallman $J R$, Sobin LH. Fibrovascular polyps of the esophagus: clinical, radiographic, and pathologic findings in 16 patients. AJR Am J Roentgenol 1996; 166: 781-7. [Crossref] 
4. Owens JJ, Donovan DT, Alford EL, et al. Life-threatening presentations of fibrovascular esophageal and hypopharyngeal polyps. Ann Otol Rhinol Laryngol 1994; 103: 838-42. [Crossref]
5. Ward MA, Beard KW, Teitelbaum EN, et al. Endoscopic resection of giant fibrovascular esophageal polyps. Surg Endosc 2018; 32: 1066 7. [Crossref] 